Conclusion: TA patients $<20$ years might experience a longer DD. Arterial hypertension seems to be a prevalent feature in TA patients $>40$ years. Vascular involvement seems also be influenced by the age of onset with the abdominal aorta being more frequently affected in younger patients and iliac arteries in older patients.Disclosure of Interests: Silvia Sartorelli: None declared, Corrado Campochiaro Consultant for: Dr Corrado Campochiaro received consultation honoraria from Pfizer., Alessandro Tomelleri: None declared, Elena Baldissera Consultant for: Consultation honoraria from Novartis and Rottapharm, Speakers bureau: Pfeizer, Sobi, Novartis, Lorenzo Dagna Consultant for: Prof Lorenzo Dagna received consultation honoraria from Abbvie, Amgen, Biogen, Bristol-Myers Squibb, Celltrion, Novartis, Pfizer, Sanofi-Genzyme, and SOBI.

DOI: 10.1136/annrheumdis-2019-eular.6066

\section{AB0614 A SINGLE, SUCCESSFUL INFLIXIMAB INFUSION FOR BEHCET'S DISEASE ASSOCIATED SIGHT- THREATENING UVEITIS ATTACK, FOLLOWED BY 2 ADDITIONAL INFUSIONS, PRODUCE LONG TERM OCULAR REMISSION}

Petros Sfikakis, Aikaterini Arida, Nikos Markomichelakis. Athens University Medical School, National and Kapodistrian University of Athens, Rheumatology Unit, 1st Dept. of Propaedeutic Internal Medicine, Joint Academic Rheumatology Program, Athens, Greece

Background: Recommendations on the use of anti-TNF agents in Behcet's disease BD include the administration of a single infusion of inflixi$\mathrm{mab}, 5 \mathrm{mg} / \mathrm{kg}$ for bilateral posterior eye segment inflammation as a firstline agent to achieve a fast-onset response (Sfikakis PP et al, Rheumatology 2007). On the other hand, long-term remission is feasible after discontinuation of successful anti-TNF treatment given for severe BD, including posterior ocular inflammation (Sfikakis PP et al. Arthritis Rheumatol 2017).

Objectives: To report the long-term outcome of successful short-term Infliximab treatment for sight-threatening uveitis in Behcet's disease. Methods: In this retrospective single-center analysis, we identified all patients with BD followed up in our center at least once yearly since 2001, who received one successful IV infusion of Infliximab (5mg/kg) for bilateral sight threatening posterior uveitis attack, followed by 2 additional infusions 2 months apart. Other severe BD manifestations at the time of attack included severe mucocutaneous disease $(n=3)$, arthritis $(n=2)$, vascular $(n=1)$, and gastrointestinal involvement $(n=1)$. The first Infliximab infusion was considered successful if complete suppression of acute ocular inflammation was achieved. Study's endpoint was the proportion of patients remaining in complete ocular remission for at least 5 years after cessation of Infliximab.

Results: We identified 10 patients (aged $52 \pm 14.3$ years, 60\% men, disease duration $12 \pm 5.2$ years) who received 3 IV Infliximab infusions (5 $\mathrm{mg} / \mathrm{kg}$ each) for sight-threatening posterior ocular inflammation (20 eyes), either at the first attack $(n=5)$ or for relapsing attacks $(n=5)$. Infliximab was given as add-on to azathioprine $(n=7)$ or to azathioprine in combination with cyclosporine $(n=2)$. Nine of ten patients $(90 \%)$ achieved the study's endpoint, i.e. after cessation of short-term Infliximab treatment remain in complete ocular remission for a mean of $9.5 \pm 4.2$ years (range 5-15.3 years). The last patient relapsed 6 months after Infliximab discontinuation, but subsequently responded to antiTNF re-treatment, which is continued to date. Notably, four of the nine patients who achieved the study's endpoint were also able to discontinue azathioprine and are currently any drug free.

Conclusion: The majority of patients with sight-threatening uveitis who responded completely to a first Infliximab infusion and received 2 additional infusions, remain in remission for many years thereafter. Additional studies to confirm that short term infliximab treatment with observation for objective improvement should be promptly administered in every BD patient with sight-threatening uveitis attack are warranted.

\section{REFERENCES}

[1] Sfikakis PP, Markomichelakis N, Alpsoy E, Assaad-Khalil S, Bodaghi B, Gul A, Ohno S, Pipitone N, Schirmer M, Stanford M, Wechsler B, Zouboulis $\mathrm{C}$, Kaklamanis $\mathrm{P}$, Yazici $\mathrm{H}$. Anti-TNF therapy in the management of Behcet's disease-review and basis for recommendations. Rheumatology (Oxford). 2007 May;46(5):736-41.

[2] Sfikakis PP, Arida A, Panopoulos S, Fragiadaki K, Pentazos G, Laskari K, Tektonidou M, Markomichelakis N. Brief Report: Drug-Free Long-Term Remission in Severe Behçet's Disease Following Withdrawal of Successful Anti-Tumor Necrosis Factor Treatment. Arthritis Rheumatol. 2017 Dec;69 (12):2380-2385.
Disclosure of Interests: None declared

DOI: 10.1136/annrheumdis-2019-eular.5494

\section{AB0615 PREVALENCE OF DEPRESSION, ANXIETY, FATIGUE AND SLEEP DISTURBANCES IN PATIENTS OF RA, SLE AND GPA}

Aman Sharma ${ }^{1}$, Abhinav Shrivastava ${ }^{1}$, Sandeep Grover $^{2}$, Saket Jha ${ }^{1}$, Gsrsnk Naidu', Manish Rathi ${ }^{3}$, Sanjay Jain ${ }^{2} .{ }^{1}$ Post Graduate Institute of Medical Education and Research, Chandigarh, Internal Medicine, Chandigarh, India; ${ }^{2}$ Post Graduate Institute of Medical Education and Research, Chandigarh, Psychiatry, Chandigarh, India: ${ }^{3}$ Post Graduate Institute of Medical Education and Research, Chandigarh, Nephrology, Chandigarh, India

Background: The relative frequencies of co-morbidities like depression, anxiety, fatigue and sleep disturbance in RA, SLE and GPA are not fully elucidated.

Objectives: To estimate and correlate the prevalence of depression, anxiety, fatigue and sleep disturbances in patients with RA, SLE and GPA by using time honored scales and PROMIS-HAQ ${ }^{1}$.

Methods: This was a cross sectional study of 183 patients (RA - 57, SLE - 64, GPA - 62). Diagnosis and assessment of depression, insomnia, anxiety and fatigue was established by patient health questionnaire 9 (PHQ 9), Epworth sleepiness scale (ESS), generalized anxiety disorder assessment scale 7 (GAD 7) and fatigue severity scale (FSS) respectively. PROMIS-HAQ short form $8 \mathrm{a}$ was also used to diagnose depression, insomnia, anxiety and fatigue and its correlation with the above time honored scales was studied.

Results: Mean age of RA, SLE and GPA patients was $45.5 \pm 12,31 \pm$ 9.5 and $42.7 \pm 13.5$ years respectively. Mean disease duration was 5.7 $\pm 5.1,3.3 \pm 2.4$ and $4.6 \pm 4$ years in RA, SLE and GPA respectively. Prevalence of depression, anxiety, fatigue, insomnia in RA, SLE and GPA as per standard scales and PROMIS HAQ is depicted in table 1 The corelation between the standard scales and PROMIS HAQ for depression [RA $(r-.816, p<.001)$, SLE $(r-0.625, p<0.001)$, GPA $(r-$ $0.772, \mathrm{p}<0.001)]$, anxiety [RA $(r-.804, \mathrm{P}<.001)$, SLE $(r-0.709$ $p<0.001)$, GPA $(0.888, \quad p<0.001)]$, sleep disturbance [RA $(r-.872$ $\mathrm{p}<0.001)$, SLE $(r-0.784, p<0.001)$, GPA $(r-0.917, p<0.001)]$ and fatigue [RA $(r-.815, p<.001)$, SLE $(r-0.798, p<0.001)$, GPA $(r-0.805, p$ $<0.001)$ ] was significant.

Table 1. Prevalence of depression, anxiety, fatigue and insomnia by various scales

\begin{tabular}{|c|c|c|c|c|c|c|c|c|}
\hline & \multicolumn{2}{|c|}{ Depression } & \multicolumn{2}{|c|}{ Anxiety } & \multicolumn{2}{|c|}{ Fatigue } & \multicolumn{2}{|c|}{ Sleep/Insomnia } \\
\hline & PHQ9 & $\begin{array}{c}\text { PROMIS } \\
\text { HAQ }\end{array}$ & GAD7 & $\begin{array}{c}\text { PROMIS } \\
\text { HAQ }\end{array}$ & FSS & $\begin{array}{c}\text { PROMIS } \\
\text { HAQ }\end{array}$ & ESS & $\begin{array}{c}\text { PROMIS } \\
\text { HAQ }\end{array}$ \\
\hline $2 \mathrm{~A}$ & $49.2 \%$ & $35.1 \%$ & $45.6 \%$ & $38.5 \%$ & $40.4 \%$ & $49.1 \%$ & $19.3 \%$ & $17.5 \%$ \\
\hline SLE & $60.9 \%$ & $43.7 \%$ & $51.6 \%$ & $40.6 \%$ & $51.6 \%$ & $57.8 \%$ & $15.6 \%$ & $14.1 \%$ \\
\hline GPA & $46.8 \%$ & $21 \%$ & $29.0 \%$ & $24.0 \%$ & $38.7 \%$ & $40.3 \%$ & $16.1 \%$ & $12.9 \%$ \\
\hline
\end{tabular}

Conclusion: Depression, anxiety, fatigue and sleep disturbance are common in RA, SLE and GPA. PROMIS HAQ has good correlation with time honoured scales for assesment of depression, anxiety, fatigue and sleep disturbance in these disorders.

\section{REFERENCES}

[1] Cella D, Riley W, Stone A, et al. The Patient-Reported Outcomes Measurement Information System (PROMIS) developed and tested its first wave of adult self-reported health outcome item banks: 2005-2008. J Clin Epidemiol 2010;63:1179-94.

Disclosure of Interests: None declared

DOI: 10.1136/annrheumdis-2019-eular.4062

\section{AB0616 HISPANIC AMERICAN PATIENTS WITH ANCA ASSOCIATED VASCULITIS AND DIFFUSE ALVEOLAR HEMORRHAGE RESPOND COMPARABLY TO INDUCTION THERAPY}

Simranjit Singh ${ }^{1}$, Francisco Quismorio ${ }^{2}$, Elizabeth Ortiz ${ }^{1}{ }^{1} L A C+U S C / K e c k$ Medical Center, Rheumatology, Los Angeles, United States of America; ${ }^{2}$ LAC+USC/Keck Medical Center, Rheumatology, Los Angeles, United States of America

Background: Hispanic American patients with ANCA-associated vasculitis (AAV) have been reported to have more severe disease and higher 